\title{
HUBUNGAN LONELINESS DAN PROBLEMATIC INTERNET USE REMAJA PENGGUNA SOSIAL MEDIA
}

\author{
Anugriaty Indah Asmarany ${ }^{1)}$ dan Nadaa Savira Syahlaa ${ }^{2)}$ \\ ${ }^{1,2}$ Fakultas Psikologi, Universitas Gunadarma ${ }^{1,2}$ \\ 1,2J1.Margonda Raya No.100, Pondok Cina, Depok 16424 \\ E-mail : anugriaty_indah@yahoo.com ${ }^{1)}$, nadaasavirasyah@gmail.com ${ }^{2)}$
}

\begin{abstract}
ABSTRAK
Penelitian ini dilatarbelakangi oleh banyaknya fenomena problematic internet use yang terjadi pada kalangan remaja pengguna sosial media. Tujuan penelitian ini adalah untuk menguji hubungan loneliness dan problematic internet use pada remaja pengguna sosial media. Penelitian ini menggunakan alat ukur berupa skala loneliness dan skala problematic internet use. Responden pada penelitian ini berjumlah 150 remaja pengguna sosial media. Teknik sampling yang digunakan adalah purposive sampling. Teknik analisis data pada penelitian ini dilakukan melalui uji secara kuantitatif dengan metode statistik korelasi dari Karl Pearson. Daya diskriminasi aitem problematic internet use bergerak dari 0,336 sampai dengan 0,521, daya diskriminasi aitem loneliness bergerak dari 0,328 sampai dengan 0,625Hasil yang didapatkan dari penelitian ini adalah terdapat hubungan yang signifikan antara loneliness dan problematic interenet use yaitu nilai koefisien korelasi sebesar 0,194 dan nilai signifikan sebesar 0,017 ( $\mathrm{p}<0,05)$. Arah hubungan positif artinya semakin tinggi loneliness semakin tinggi problematic internet use pada remaja pengguna sosial media, sebaliknya semakin rendah loneliness semakin rendah problematic internet use pada remaja pengguna sosial media.
\end{abstract}

Kata kunci: Loneliness, Problematic internet use, Pengguna sosial media, Remaja.

\section{PENDAHULUAN}

Pada hakikatnya manusia adalah makhluk sosial. Meski secara fisik manusia dapat berdiri sendiri, namun secara psikologi manusia membutuhkan orang lain. Dalam menjalin hubungan dengan sesama, manusia tak lepas dengan komunikasi. Berbagai sarana dan prasarana yang digunakan manusia dalam berkomunikasi sangatlah beragam salah satunya yaitu internet.

Tsao \& Steffes-Hansen (2008) semua kalangan dapat dengan mudah mengakses internet terutama bagi remaja. WeAreSocial yang bekerja sama dengan Hootsuite melansir Global Digital Report tahun 2018, melaporkan jumlah pengguna internet di Indonesia 132 juta orang. Penggunakan internet selama 8 jam 51 menit setiap harinya dan didominasi oleh aktifitas bersosialisasi di dunia maya. Durasi orang Indonesia menggunakan sosial media sebesar 3 jam 23 menit. Haryanto (2017) Mayoritas sosial media yang diakses pengguna internet antara lain YouTube, Facebook, Instagram, Twitter, WhatsApp, email, Searching, dan yang terkahir menonton video.

Internet memiliki dampak positif dan negatif. Salah satu yaitu penggunaan yang berlebihan (adiktif) sehingga membuat orang memiliki dunia sendiri. Beard dan De Abreu (2001) adiktif atau maldiktif ialah merupakan kondisi yang juga dikenal dengan istilah problematic internet use. Caplan, Williams \& Yee (2009) problematic internet use merupakan sindrom multidimensional yang terdiri dari gejala kognitif, emosional, dan perilaku yang mengakibatkan kesulitan seseorang dalam mengelola kehidupannya disaat offline.
Morahan-Martin (1999) terdapat beberapa faktor yang menyebabkan seseorang mengalami problematic internet use, yakni faktor-faktor psikososial seperti depresi, loneliness, kecemasan sosial, dan sifat pemalu.

Salah satu faktor penyebab problematic internet use adalah loneliness. Loneliness terjadi ketika individu merasakan perbedaan antara tingkat interaksi sosial, dukungan, dan keintiman yang diinginkan dengan yang diraih. Hasil penelitian Panicker dan Sachdev (2014) remaja menggunakan internet untuk membantu meringankan perasaan tidak menyenangkan seperti stres, loneliness, depresi, kecemasan dan masalah lainnya dalam kehidupan nyata.

\section{RUANG LINGKUP}

Adapun ruang lingkup dari penelitian ini melakukan pengujian secara empiris hubungan antara loneliness dan problematic internet use pada remaja pengguna sosial media.

\section{BAHAN DAN METODE}

Disajikan kajian teori dan metodologi dari penelitian ini:

\subsection{Problematic Internet Use}

Caplan, Williams \& Yee (2009) problematic internet use adalah sindrom multidimensional yang terdiri dari gejala kognitif, emosional, dan perilaku yang mengakibatkan kesulitan seseorang dalam mengelola kehidupannya disaat offline. Tokunaga \& Rains (2010) problematic internet use, adalah kecanduan internet, 
penyalahgunaan internet, ketergantungan Internet, dan penggunaan Internet kompulsif, mengacu pada keterikatan yang tidak sehat dengan teknologi berbasis Internet.

Shapira, Goldsmith, Keck, Khosla \& McElroy (2000) problematic internet use, adalah sikap yang tidak dapat dikendalikan, sangat menyusahkan, memakan waktu atau mengakibatkan kesulitan sosial, pekerjaan atau keuangan dalam penggunaan internet. Jadi, dapat disimpulkan bawah problematic internet use, adalah kecanduan internet, penyalahgunaan internet, ketergantungan internet, dan penggunaan Internet kompulsif yang mengakibatkan kesulitan seseorang dalam mengelola kehidupannya disaat offline.

Terdapat tiga karakteristik individu yang mengalami problematic internet use menurut Caplan, (2003), antara lain yaitu Individu yang menderita persoalan psikososial seperti depresi dan loneliness, Individu lebih banyak melakukan interaksi sosial secara online sebagai alternatif dari komunikasi tatap muka karena dianggap kurang mengancam, Keinginannya untuk selalu interaksi secara online membuat individu tersebut memiliki persoalan interaksi sosial lewat internet yang berlebihan dan kompulsif sehingga berdampak pada bidang kehidupannya yang lain

Loneliness

Peplau \& Perlman (dalam Margalit, 2010) loneliness adalah pengalaman tidak menyenangkan ketika individu merasakan perbedaan antara pola hubungan sosial yang diinginkan dengan hubungan sosial yang dicapai. Baumeister \& Vohs (2007) didefinisikan sebagai pengalaman menyedihkan yang terjadi ketika hubungan sosial seseorang yang dianggap kurang dalam kuantitas, terutama dalam kualitas yang diinginkan. Woodward (dalam Margalit, 2010), loneliness adalah perasaan sendirian dan terputus atau terasingi dari orang, tempat, dan benda.

Asher (dalam Margalit, 2010), loneliness adalah ketidakpuasan menyeluruh dari kualitas dan kuantitas hubungan timbal balik dan saling mempengaruhi antara individu dengan individu, kelompok dengan kelompok, serta antara individu dengan kelompok (interelasi sosial individu). Menurut Suparno (2007) loneliness adalah keadaan batin seseorang yang merasakan loneliness, tidak ada yang dapat diajak berkomunikasi, diajak membangun persaudaraan, ada unsure kekeringan, hati tidak tenang, merasa dipisahkan dari sesuatu. Jadi dapat disimpulkan bahwa loneliness adalah keadaan mental dan emosional yang terutama dicirikan dengan adanya perasaan kekurangan dan ketidakpuasan karena tidak memiliki hubungan yang bermakna dengan seseorang dan terjadi kesenjangan antara hubungan sosial yang diinginkan dengan hubungan sosial yang dimiliki individu.

Terdapat tiga aspek - aspek Loneliness menurut Russell (1996), yaitu, Personality atau kepribadian individu dari sistem-sistem psikofisik yang menentukan karakteristik perilaku dan berfikir, Social desirability yaitu adanya keinginan kehidupan sosial yang disenangi inividu pada kehidupannya dilingkungannya, dan Depression, adanya tekanan dalam diri yang mengakibatkan adanya depresi.

\subsection{Metode Penelitian}

Desain penelitian ini menggunakan metode penelitian kuantitatif dengan metode statistik korelasi dari Karl Pearson. Populasi subjek dalam penelitian ini adalah remaja pengguna sosial media yang berusia 12-21 tahun dan sampel penelitian ini adalah remaja yang menggunakan internet. Populasi subjek dalam penelitian ini adalah remaja yang berusia 12-21 tahun dan sampel penelitian ini adalah remaja yang menggunakan internet. Penelitian ini menggunakan teknik purposive sampling, yaitu teknik penetapan sampel dengan cara memilih sampel diantara populasi sesuai dengan yang dikehendaki peneliti, sehingga sampel tersebut dapat mewakili karakteristik populasi yang telah dikenal sebelumnya. Adapun batasan lain dari penelitian ini yaitu remaja berusia 12-21 tahun yang memiliki dan menggunakan media sosial (instagram, facebook, twitter, youtube), memiliki dan menggunakan chatting app (Whatsapp dan line), memiliki dan menggunakan email, minimal aktif menggunakan internet selama $>3,5$.

Dalam menghitung validitas alat ukur problematic internet use dan loneliness peneliti menggunakan uji validitas isi dengan cara meminta masukan dari seorang ahli, dalam hal ini dosen pembimbing yang ahli dalam bidanag pengukuran psikologis. Setelah itu kedua skala dijadikan ke dalam bentuk kuesioner dengan penampilan yang menarik agar terciptanya minat dalam pengisian alat tes tersebut.

Problematic internet use ini diukur menggunakan skala Generalized problematic internet use scale (GPIUS) yang diadaptasi dari Pontes, Caplan, \& Griffiths (2016) yang dikembangan berdasarkan dimensi problematic internet use, menurut Caplan (2010) yang meliputi: Preference for online social interaction, mood regulation, deficient self regunation (cognitive preoccupation dan compulsive internet use), dan negative outcome. Skala ini terdiri dari 15 aitem favorable untuk mengukuru problematic internet use. Untuk mengukur bobot skornya Sangat Setuju $=5$, Setuju $=4$, Netral $=3$, Tidak Setuju $=2$, dan Sangat Tidak Setuju $=1$.

Alat ukur loneliness menggunakan skala ukur loneliness scale version 3 (UCLA version 3) yang dikembangan berdasarkan aspek-aspek loneliness menurut Russell (1996) yang ,meliputi: aspek personality atau kepribadian, aspek social desirability, dan aspek depression. Skala ini terdiri dari 15 aitem, 9 aitem favorable dan 6 unfavorable untuk mengukur loneliness. Untuk pentanyaan favorable bobot skornya Selalu $=4$, Terkadang $=3$, Jarang $=2$, dan Tidak pernah $=1$. Sedangkan untuk pertanyaan unfavorable bobot skrornya adalah Selalu $=1$, Terkadang $=2$, Jarang $=3$, dan Tidak pernah $=4$. 


\section{PEMBAHASAN}

Disajikan hasil dan pembahasan dari penelitian ini

\subsection{Daya Diskriminasi Aitem}

Perhitungan dalam penelitian ini dilakukan dengan bantuan aplikasi SPSS versi 21. Berdasarkan uji daya diskriminasi aitem yang telah peneliti lakukan pada skala problematic internet use, diperoleh hasil bahwa dari 15 aitem semuanya memiliki daya diskriminasi aitem yang baik. Koefisien pada semua aitem yaitu antara 0,336 sampai 0,521 .

Berdasarkan uji daya diskriminasi aitem yang telah peneliti lakukan pada skala loneliness, diperoleh hasil bahwa dari 15 aitem yang diuji terdapat 12 aitem baik dan 3 aitem yang gugur. Koefisien pada aitem-aitem yang baik yaitu antara 0,328 sampai dengan 0,625.

\subsection{Reliabilitas}

Pada hasil uji reliabilitas skala problematic internet use dalam penelitian ini diperoleh nilai koefisien skala problematic internet use sebesar 0,793, hasil tersebut dapat dikatakan memiliki reliabilitas yang baik. Pada hasil uji reliabilitas skala loneliness dalam penelitian ini diperoleh nilai koefisien skala loneliness sebesar 0,818 , hasil tersebut dapat dikatakan memiliki reliabilitas yang baik.

\subsection{Normalitas}

Berdasarkan uji normalitas yang dilakukan diketahui bahwa signifikansi problematic internet use sebesar 0.004 dan signifikansi loneliness sebesar 0.002, hasil tersebut menunjukkan bahwa problematic internet use dan loneliness berdistribusi tidak normal.

\subsection{Linearitas}

Linearitas Berdasarkan uji linearitas yang dilakukan diketahui bahwa signifikansi loneliness dan problematic internet use sebesar 0,013 yang artinya bersifat linear.

\subsection{Hipotesis}

Pada penelitian ini analisis yang digunakan adalah analisis statistic. Product Moment Person dengan teknik korelasi bivariate, dengan melihat hasil nilai signifikan $(\mathrm{p} \leq 0,005)$ maka hipotesis diterima. Analisis ini dilakukan untuk menguji sejauh mana hipotesis diterima. Analisis ini dilakukan untuk menguji sejauh mana hubungan antara dua variabel. Pada penelitian ini hipotesis yang diajukan adalah terdapat hubungan antara loneliness dan problematic internet use pada remaja.Berdasarkan hasil analisis data yang dilakukan dengan menggunakan teknik korelasi person (2-tailed), diketahui nilai koefisien korelasi sebesar 0,194 dengan nilai signifikan sebesar $0,017(\mathrm{p}<0,05)$ yang berarti terdapat hubungan positif yang signifikan antara loneliness dan problematic internet use pada remaja. Arah korelasi pada penelitian ini bersifat positif, hal tersebut menunjukan bahwa, semakin tinggi loneliness maka semakin tinggi problematic internet use, atau sebalikanya semakin rendah loneliness maka semakin rendah problematic internet use.

\subsection{Analisis Deskriptif}

Berdasarkan analisis data diketahui mean hipotetik pada skala Problematic internet use sebesar 45, nilai standar deviasi sebesar 10 dan mean empirik sebesar 46,62 yang artinya responden dalam penelitian ini termasuk dalam kategori sedang. Berdasarkan analisis data diketahui mean hipotetik pada skala loneliness sebesar 30, nilai standar deviasi sebesar 6 dan mean empirik sebesar 27,06 yang artinya responden dalam penelitian ini termasuk dalam kategori sedang. Hasil tersebut dapat menunjukkan bahwa responden pada penelitian ini cukup merasa problematic internet use karena merasa loneliness.

Berdasarkan penelitian yang dilakukan, dapat disimpulkan bahwa hipotesis dalam penelitian ini diterima, yang berarti terdapat arah hubungan positif yang signifikan antara loneliness dan problematic internet use pada remaja, artinya semakin tinggi loneliness maka semakin tinggi problematic internet use, atau sebalikanya semakin rendah loneliness maka semakin rendah problematic internet use. ). Sesuai dengan hasil penelitian yang dilakukan oleh Huan, Ang, dan Chye (2014) yang menyatakan bahwa ada korelasi antara loneliness dan problematic internet use. Hal tersebut sesuai dengan teori yang dikemukan oleh Morahan-Martin (1999) yang menyatakan beberapa faktor yang menyebabkan seseorang mengalami problematic internet use, yakni faktor-faktor psikososial seperti depresi, loneliness, kecemasan sosial, dan sifat pemalu.

Arah korelasi pada penelitian ini bersifat positif, hal tersebut meunjukan bahwa semakin tinggi loneliness yang dirasakan maka semakin tinggi problematic internet dan sebaliknya semakin rendah loneliness maka semakin rendah problematic internet. Sesuai dengan yang dilakukan oleh penelitian yang dilakukan oleh Ang, Chong, Chye dan Huan (2012) yang menyatakan bahwa loneliness memiliki korealsi yang positif dengan problematic internet use pada siswa SMP. Hal ini juga didukung oleh penelitian yang dilakukan oleh Odaci dan Kalkan (2010), yang menyatakan bahwa loneliness memiliki hubungan yang positif dengan problematic internet use pada mahasiswa.

Hasil perhitungan mean empirik total pada variabel loneliness termasuk dalam kategori sedang, dan juga hasil perhitungan mean empirik total pada variabel problematic internet use juga dalam kategori sedang. Dari data yang diperoleh dapat disimpulkan bawah responden dalam penelitian ini memiliki problematic internet use yang sedang (mengarah tinggi) dan loneliness yang rendah (mengarah sedang). Hal tersebut didukung oleh Ceyhan dan Ceyhan (2008), bahwa ada hubungan positif pada loneliness dan problematic internet use, dengan loneliness sebagai faktor penyebab 
kedua problematic internet use setelah depresi sebegai faktor penyebab pertama.

Hasil penelitian mean empirik problematic internet use berdasarkan jenis kelamin, laki-laki memiliki mean sebesar 46,67 dan perempuan 46,60, keduanya berada pada kategori sedang, namun skor mean pada laki-laki lebih tinggi dibanding perempuan. Menurut Eroglu, Pamuk, dan Pamuk (2013), hal ini disebabkan karena laki-laki cenderung lebih terkait dengan hobi nya, dan dapat melakukan hobinya tersebut melalu internet.

Pada penelitian ini, mean empirik problematic internet use yang berusia 15-17 tahun memiliki mean sebesar 48,56, 18-20 tahun memiliki mean sebesar 43,82, dan 21-22 tahun memiliki mean sebesar 47,56. Ketiga kelompok berada pada kategori sangat tinggi, namun skor mean pada subjek yang berusia 15-17 tahun paling tinggi dibandingkan usia 18-20 tahun dan 21-22 tahun. Hal ini sesuai dengan data yang terdapat pada Asosiasi Penyelenggara Jasa Internet Indonesia (APJII) pada tahun 2017 yang menyatakan pengguna internet di Indonesia berdasarkan usia yaitu, usia 13-18 tahun berjumlah 49,52\%, usia 19-34 tahun berjumlah 16,68, usia 35-54 tahun berjumlah $29,55 \%$, dan usia diatas 54 tahun bejumlah $4,24 \%$.

Pada mean empirik problematic internet use berdasarkan pekerjaan, responden yang berprofesi sebagai pelajar memiliki mean sebesar 46,15, mahasiswa memiliki mean 48,36, karyawan swasta memiliki mean sebesar 46,33 dan wirausaha memiliki mean sebesar 48 . Semuanya berada pada kategori sedang, namun nilai mean mahasiswa menunjukan angka yang lebih tinggi daripada pelajar, karyawan swasta, dan wirausaha. Hal ini sesuai dengan penelitian yang dilakukan oleh Sari dan Aydin (2014) menyatakan bahwa mahasiswa memiliki akses internet yang lebih luas ke internet. Di Indonesia, berdasarkan Asosiasi Penyelenggarn Jasa Internet Indonesia (APJII) jumlah pengguna internet pada tahun 2017 didominasi oleh oleh kelompok usia 13-34 tahun.

\section{KESIMPULAN}

Berdasarkan penelitian yang dilakukan, dapat disimpulkan bahwa hipotesis dalam penelitian ini diterima, yang berarti terdapat arah hubungan positif yang signifikan antara loneliness dan problematic internet use pada remaja, artinya semakin tinggi loneliness maka semakin tinggi problematic internet use, atau sebalikanya semakin rendah loneliness maka semakin rendah problematic internet use). Hasil perhitungan mean empirik total pada variabel loneliness termasuk dalam kategori sedang, dan juga hasil perhitungan mean empirik total pada variabel problematic internet use juga dalam kategori sedang.

\section{SARAN}

Berdasarkan hasil penelitian dan pembahasan yang telah peneliti jelaskan di atas, maka terdapat beberapa saran yang dapat diberikan, antara lain:
1. Saran untuk Remaja pengguna sosial media Diharapkan dapat mengendalikan penggunaan internet yang berlebihan dan penggunaan internet yang tidak sewajarnya, dengan cara mengontrol diri dalam penggunaan internet, misalnya memberikan batasan waktu jam perhari sebagai batasan agar tidak terjadi problematic internet use. Cobalah untuk berinteraksi sosial secara langsung agar tidak mengalami problematic internet use. Remaja diharapkan bila merasa loneliness segeralah mencari sahabat dan teman teman yang paling dekat dan cobalah untuk melakukan aktifitas yang baik secara sosial dan secara nyata, dan melakukan komunikasi yang baik dengan orang tua serta meceritakan apapun yang sedang dirasakan kepada orang tua.

2. Saran untuk Orang Tua

Diharapkan dapat memberi perhatian lebih dengan mengontrol serta mengawasi penggunaan internet pada remaja agar internet dapat digunakan remaja tidak secara berlebihan, dan sesuai dengan kebutuhan saja. Orang tua juga diharapkan menjalin hubungan komunikasi yang baik dengan anak agar anak tidak merasakan loneliness karena merasa tidak adanya dukungan sosial yang didapatkan dari orang tua.

3. Saran untuk Masyarakat

Diharpakan dapat mengenali serta memahami dampak baik dan buruk dari penggunaan internet, serta mengontrol penggunaan internet sehingga tidak mengalami problematic internet use dan juga bersosialisasi di lingkungan secara nyata agar terhindar dari loneliness.

4. Saran untuk Penelitian selanjutnya

Diharapkan mampu mengembangkan penelitian ini lebih lanjut berdasarkan hasil penelitian ini dengan melakukan penelitian lain dengan subjek yang berbeda seperti hubungan loneliness dan problematic internet use pada orang dewasa atau pada karyawan yang telah pensiun. Diharapkan juga melakukan penelitian lain mengenai variabel lainnya seperti problematic internet use dengan depresi atau kecemasan sosial karena berdasarkan penelitian ini loneliness tidak terlalu kuat mempengaruhi perilaku problematic internet use.

\section{DAFTAR PUSTAKA}

Baumeister, R. F., \& Vohs, K. D. 2007. Social psychology. London: SAGE publication Ltd.

Beard, K. W., \& DeAbreu, C. N. (2011). Modification in the proposed diagnostic criteria for internet addictio. Cyberpsychology \& Behavior, 4(3), 377383.

Caplan, S. E. 2003. Preference for online social interaction a theory of problematic internet use and psychosocial well-being. Communication research, 30(6), 625-648. 
Caplan, S. E., Williams, D., \& Yee, N. 2009. Problamatic internet use and psychosocial wellbeing among MMO players. Computers in Human Behavior, 25, 1312-1319.

Caplan, S. E. 2010. Theory and measurement of generalized problematic Internet use: A two-step approach. Computers in Human Behavior, 26, 1089-1097.

Haryanto, F. 2017. Data bicara, orang Indonesia internetan $8 \mathrm{jam} / \mathrm{hari!}$ Ini yang diakses. https://www.brilio.net/gadget/data-bicara-orangindonesia-internetan-8-jamhari-ini-yang-diakses170806w.html. 24 April 2018.

Margalit, M. 2010. Lonely children and adolescents. Israel: Constantiner school of educatio.

Morahan-Martin, J. 1999. The relationship between loneliness and internet use and abuse. CyberPsychology and Behavior, 2(5), 431-439.

Panicker, J., \& Sachdev, R. 2014. Relation among loneliness, depression, anxiety, stress, and problematic internet use, 9(2), 1-10.

Pontes, H, M., Caplan, S, E., \& Griffiths, M, D. 2016. Psychometric validation of the generalized problematic internet use scale 2 in a Portuguese sample. Computers in Human Behavior, 63, 823833.

Russell, D.W. 1996. UCLA Loneliness Scale (Version 3): Reliability, Validity, and Factor Structure. Journal of Personality Assessment, 66, 20-44.

Shapira, N. A., Goldsmith, T. D., Keck, P. E., Khosla, U. M., \& McElory, S. L. 2000. Psychiatric features of individuals with problematic internet use. Journal of Affective Disorders 57, 267-272.

Suparno, P. 2007. Seksualitas kaum berjubah. Yogyakata: Kanisius.

Tokunaga, R. S., \& Rains, S. A. 2010. An evaluation of two characterizations of the relationships between problematic internet use, time spent using the internet, and psychosocial problems. Human communication, 36, 512-545.

Tsao, J., \& Steffes-Hansen, S. 2008. Predictors for internet usage of teenagers in the united states. A multivariate analysis, 14(3), 171-191. 